\title{
Imágenes en movimiento y política en el Chile de la post dictadura
}

\section{Motion pictures and politics in the post-dictatorship Chile}

\section{María Eugenia Horvitz Vásquez}

Facultad de Filosofía y Humanidades, Universidad de Chile

mhorvitz@uchile.cl

\section{Resumen}

En el tratamiento de la historia reciente se presentan problemas teóricos y metodológicos a la hora de considerar los archivos provenientes de la subjetividad, representada en las imágenes fílmicas. Entre las dificultades más importantes está la relación del cine con la política, cuando se refiere a las propuestas de distintas memorias en un campo en disputa. Podría afirmarse que las imágenes en movimiento, así como la oralidad, ya están en la historia y que la historiografía debe interpretar críticamente, utilizando otros archivos, pero no desconociendo las subjetividades, portadoras de representaciones colectivas en periodos de crisis de las confianzas públicas.

Palabras clave: Teoría crítica, política, cine, memoria, historia.

\begin{abstract}
In the treatment of recent history, some theoretical and methodological issues are presented when it's time to consider the archives that come from subjectivity which is represented in filmic images. Among the most important difficulties is the relation between motion pictures and politics, when it refers to the proposals from different memories in a disputed field. You could affirm that the moving images, as well as oral tradition, already are in history, and historiography must interpret critically using other archives, not ignoring subjectivities who are bearers of collective representations in times of crisis in the public trusts.
\end{abstract}

Keywords: Critical theory, political studies, film, collective memory, history. 
El deseo social por las imágenes ha sido constante, como se puede evidenciar en todas las culturas si nos remontamos en el tiempo. En las sociedades contemporáneas, como lo precisa Rancière (1998, p. 35), los sujetos emancipados lograron crear sus relatos usando la ciencia y la técnica, efectuando la mímesis con la realidad a través de la fotografía y luego del cine. Se pudo dejar ver. El productor de imágenes y su espectador-testigo, entraban en una relación particular de sorpresas y narraciones del mundo que no se sometía a los cánones anteriores. No era necesario saber, se lograba adquirir directamente una historia plagada de experiencias individuales y colectivas, reconocer signos y emblemas representativos de distintos grupos sociales.

Desde este enfoque, las memorias trasportadas en los relatos cinematográficos con su fidelidad a lo vivido, pero inmersos en las identidades colectivas, son fuentes que vinculan discursos y prácticas sociales. Como lo ha expresado Louis Marin a propósito de las imágenes:

“( ... ) así se asignan a la representación un doble sentido, una doble función: hacer presente una ausencia, pero también exhibir su propia presencia como imagen, y constituir con ello a quien la mira como sujeto que mira ... El cine es una copia del mundo, pero copia fiel" (Chartier, 1999, p. 78).

Este valor del cine puede abrir a la investigación histórica nuevas posibilidades que, entrecruzadas con las fuentes canónicas, permitirían llevar a re-significar de otro modo la historia reciente. Sin embargo, en la historiografía, el camino de aceptación de la subjetividad ha estado en disputa en los últimos cincuenta años. La memoria de los testigos de las "grandes catástrofes" contemporáneas o las imágenes en movimiento rompían los cánones aceptados por la disciplina, en las hipótesis y prácticas historicistas o positivistas, que requerían de un discurso objetivo y distanciado de los acontecimientos, basados en las fuentes consagradas para la posteridad, resguardadas en archivos oficializados. El "uso público de la historia", siguiendo el planteamiento de Habermas (2000), tenía baluartes que impedían dejar entrar estas luces y sombras provenientes de las comunidades vencidas o excluidas, las que llegaron a ser más cuantiosas que las anotadas en los reservorios históricos, puesto que las mujeres, las minorías étnicas, los perseguidos, los olvidados por los poderes de distinta naturaleza hicieron tardíamente sus entradas en el panteón de lo memorable.

La apertura para concebir el que los interrogantes del historiador parten desde el presente, como lo advirtiera Marc Bloch en sus escritos desde el campo de concentración de Buchenwald fue desoída por algún tiempo. No obstante, los reclamos sociales y diversos aportes teóricos fueron abriendo paso a pensar que la memoria es siempre social, como lo observara Maurice Halbwachs en Los marcos sociales de la memoria (1925); el tiempo del recuerdo se reconstruye sobre la base del lenguaje y los parámetros sociales establecidos y colectivamente valorados con las 
influencias de los grupos, las clases, las religiones. Por otra parte, los aportes de Freud, haciendo hincapié en la importancia del lenguaje como expresión común para poder recordar y decir, así como los de Bergson, resaltando la importancia de la experiencia, contribuyeron a considerar la subjetividad inmersa en las representaciones colectivas, dejando atrás las concepciones de la memoria aislada, solo expresión de las referencias personales.

En lo que se refiere a las imágenes en movimiento o a la fotografía, hubo un transcurso similar en los enfoques sobre los tiempos de las guerras europeas que han estado en la base de los estudios actuales. Entre los primeros que pusieron el acento en la importancia del cine para comprender una sociedad en una época determinada está Siegfried Kracauer, que en 1946 escribirá De Caligari a Hitler Une Histoire Psychologique du Cinéma Allemand, postulando que el conocimiento histórico debiera reservar un área de conocimiento para estos estudios, diciendo que:

“(..) los films son particularmente comprensibles en virtud de sus 'jeroglíficos visibles' que complementan el testimonio de la historia misma. Amalgamando a la vez la historia y eso que vemos, 'la dinámica invisible de las relaciones humanas' es más o menos característico de la vida interior de la nación que ha producido las películas (...) Siempre es posible que ciertos motivos cinematográficos sean característicos de una parte solamente de la nación, pero esta consideración no perjudica la existencia de tendencias que afectan a una nación en su conjunto" (2009, pp. 8-9).

Agregando más adelante que "en la Alemania pre-nazi los intereses de las clases medias penetraron en todas los grupos de la sociedad" (2009, p. 9). Este libro entrega una metodología para el estudio de cada uno de los films que analiza, pero ha sido discutida su visión entre la sociología y la psicología para interrelacionar cine e historia. Sin embargo, su aproximación pionera para relevar las representaciones colectivas en las imágenes en movimiento fue un llamado de atención hacia un campo inexplorado.

De esa época provienen algunos de los planteamientos más interesantes de Walter Benjamin sobre La obra de arte en la época de la reproductibilidad técnica (2007) ${ }^{1}$. El autor pone el acento en la ruptura de la tradición unida a la autenticidad de la obra de arte, a su "aura" de única e irrepetible,

1 Este trabajo de Benjamin tuvo distintas versiones entre 1935 y 1939. La que consideramos es la publicación póstuma en Sobre la Fotografía, Edición Pre-textos, Colegio de España en París, España, 2007. 
“( ... ) al multiplicarse las reproducciones, sustituye la ocurrencia irrepetible de lo reproducido por su ocurrencia masiva. Esta técnica, además actualiza lo reproducido al permitir a la reproducción salir al encuentro del receptor en cualquier contexto en que se halle. Estos dos procesos dan lugar a una poderosa subversión de lo trasmitido por la tradición” (p.97).

Escribiendo más adelante que en el momento en que el criterio de la autenticidad deja de funcionar en la producción artística, toda la función del arte queda subvertida. En lugar de fundamentarse en el ritual pasa a fundamentarse en una praxis distinta: a saber, en la política. Para Benjamin, estas técnicas se reflejan en la fotografía y el cine que adquieren su fuerza propia, como también en la reproducción de las obras de la pintura, la escultura o la música que se acercan espacial y humanamente, a la "aspiración tan ardiente de las masas actuales" (2007, p. 99).

Estas reflexiones de Kracauer o Benjamin que se suscitaron en la época de la "catástrofe" más definitiva de las expectativas de la Modernidad, subrayan la importancia de la praxis política. El dejar ver y escuchar en cada contexto histórico está permeado por representaciones sociales y culturales cuyos signos y lenguajes pueden ser emancipatorios o estar dirigidas por poderes y saberes para la dominación masiva.

Las imágenes en movimiento, cuando solo eran presentaciones experimentales, productos para "las ferias de diversiones", no concitaron el interés de los Estados o de distintos grupos de presión política. En la medida en que adquirieron una influencia o deseo masivo, llegaron a ser objetos de control o de uso. Justamente, desde los años 20 del siglo pasado, el cine o la fotografía pasaron a ser productos representativos de las disputas políticas de manera visible, puesto que la memoria no oficial todavía no irrumpía en el espacio público.

La tentación autoritaria de "las masas", parafraseando a Benjamin, entre otros ejemplos tuvo una película como El Judío Suss (1940), que señalaba al culpable histórico, representativo de la crisis que se vivía en sociedades en que el miedo se sentía y encarnaba. El poder del nazismo se manifestó en las obras de Leni Riefensthal, que con gran maestría en El triunfo de la voluntad (1935) muestra sin dejar respiro el dominio del dictador y de sus tropas de guerra. Son algunos ejemplos conocidos de las apuestas para sensibilizar y lograr la unidad de los grupos que veían la necesidad de encontrar un amparo poderoso delegando la autonomía ciudadana.

Si nos guiamos por la cronología histórica, después de las guerras civiles europeas, las reflexiones anticipatorias pusieron en jaque no solo a los poderes y saberes, sino que también las experiencias masivas. En la creación, así como en los movimientos sociales, se abrieron espacios para el recuerdo, la denuncia y la exigencia. Desde el cine, el realismo italiano puso a navegar las otras miradas patentes en Roma Ciudad Abierta (1944) o El Ladrón de Bicicletas (1947), también el cine documental 
mostró la indecencia del terror de los campos de concentración en Noche y Niebla (1955), a través de las autorías de Resnais y Cayrol para mencionar los movimientos imparables, a pesar de la Guerra Fría. En el caso de América Latina y en particular en Chile -como lo sabemos-, floreció el documental para registrar a los olvidados y sus acciones que representaban el malestar de sociedades que buscaban por caminos distintos la emancipación social.

La historiografía más pausadamente y como lo mencionamos, recibió el doble impacto de las teorías y de los movimientos sociales. La apertura para hacer parte de la historia contemporánea al testigo de las catástrofes y a los excluidos de los archivos oficiales experimentó un cambio que todavía es objeto de debate. En cuánto a la entrada de la subjetividad, en particular de las imágenes en movimiento, tuvo sus pioneros: en 1974 Marc Ferro lanzó la propuesta para abrir esa área del conocimiento a que se refería Kracauer (1974), la de los archivos fílmicos en oposición a lo que llamó la historia oficial, que tenía su contra historia en las imágenes en movimiento. La historia de las representaciones colectivas dio nuevo impulso a considerar las subjetividades y sus contextos, que de modo distinto desarrollaron Georges Duby, Michel Vovelle o Roger Chartier. De esta manera "el uso público de la historia" pasó a abrirse desde y hacia otras narraciones, que desde la oralidad, la escritura y la imagen permitían que la memoria y sus demandas, siempre como pasados del presente, al decir de Paul Ricoeur (2004), tuvieran ecos sociales difíciles de restringir. Por su parte, Miguel Rojas Mix (2006) advierte que “( ... ) en las últimas décadas del siglo $\mathrm{XX}$, se ha verificado en forma radical la transición epistemológica que representa el paso de una forma de conocimiento a otra. Transitamos de la civilización del texto leído a la civilización del texto visto” (p. 19).

En el tratamiento de la historia reciente parece imprescindible que la subjetividad y sus lenguajes portadores de las representaciones culturales y sociales necesiten de metodologías particulares, pero no pueden ser excluidos de la investigación y la expresión crítica propia del discurso histórico. En igual medida, no se logra una visión de una época sin resolver una pregunta fundamental planteada por Chartier:

“icómo pensar las relaciones que mantienen las producciones discursivas y las prácticas sociales? Hacer inteligibles las prácticas que las leyes de formación de los discursos no gobiernan es una empresa difícil, inestable, situada al borde del acantilado', como escribe de Certau a propósito de Vigilar y Castigar..." (1999, p. 6).

En esta comunicación me ha interesado abordar las dificultades epistémicas de la triple relación historia-cine-memoria desde las prácticas sociales, que necesitan aproximaciones teóricas para acercarse a los lenguajes, signos, iconos y emblemas transportados por las subjetividades que están anclados en las representaciones 
culturales colectivas en disputa política. Estamos lejos de una historia unívoca que simbolice los pasados sin fracturas para el bien de la unidad de la nación o de la patria.

Me ha parecido, por la vía del ejemplo, considerar algunas interrogantes históricas que los cineastas, antes que los historiadores, han puesto en el ámbito público que invitan a explicarnos ciertos problemas de la historia reciente: la tentación autoritaria en ciertos grupos sociales y políticos; los silencios sobre el pasado reciente, las expresiones de los movimientos sociales durante la dictadura.

\section{De la memoria en el cine}

Las políticas públicas relativas a la memoria reciente ${ }^{2}$, podrían mirarse como el cierre de la conmoción pública por los efectos del terrorismo de Estado. No obstante, para los represaliados, los ofendidos, así como para los partidarios de la Dictadura, más que un final se ha tratado del comienzo del reconocimiento de la verdad reclamada, y para los otros, una simple borradura de los éxitos del Dictador. Más que un debate es la presencia en la escena pública de una pugna manifiesta en el campo de la memoria. Además, lo que podría pensarse como una pacificación ante el miedo para unos, y una nostalgia del poder para los otros, nos pone ante una reflexión de Hanna Arendt (2008) que nos retrotrae al tiempo de los orígenes de la dictadura: "( ... ) pero esta sed de poder nacida del miedo nunca puede ser aplacada, pues el miedo y la desconfianza mutua hacen imposible 'actuar en concierto"' (p. 105).

El miedo en el inicio de la Dictadura ante las promesas de la inclusión social y la ampliación de la democracia en el Gobierno del Presidente Allende, se ha transformado entre algunos en "una sed de poder" que, a mi modo de ver, es una tentación autoritaria de ciertos grupos que están en la sociedad, cuyos lenguajes y emblemas no han cambiado en el transcurso del tiempo. En I love Pinochet (2002), la cineasta Marcela Said nos los presenta en un momento emblemático, la llegada de Pinochet desde la prisión en Londres, ciertamente era un momento final del gran poder del Dictador que todavía era senador vitalicio y seguía teniendo una impronta importante en la FFAA, baste recordar que al pie de avión que lo devolvía a Chile, lo esperaba el Comandante en Jefe del Ejército. Los distintos procesos a lo que fue sometido no podían augurarse, menos aún los referidos a la sustracción de los fondos del Estado.

Lo interesante de la obra de Said es haber captado en ese momento el lenguaje en sus formas y sentido de grupos dispares socialmente que defendían la dictadura y todos sus logros, particularmente, la aceptación de la tortura, los detenidos desaparecidos,

2 Informe de verdad y reconciliación (1991), Tortura y Prisión Política (2006). 
las limitaciones a las libertades individuales y públicas. El autoritarismo continuaba sin cambios, no es que no supieran sobre el horror, más bien eran co-partícipes amenazantes; el héroe había vuelto y se podía esperar una nueva oportunidad, incluso varios de los entrevistados son aún representantes políticos. Sobre el carácter y características de la derecha en Chile poseemos importantes estudios, pero la imagen y el habla de esos testigos nos dejan ver que se encuentran en grupos sociales distintos, que la memoria del héroe continúa sin reparos. En los últimos dos años han reaparecido nuevamente, reuniéndose y volviendo a usar el mismo léxico, probablemente por la impronta de los movimientos sociales encabezados por los estudiantes.

Lo que nos interesa relevar es la importancia de este registro de la tentación autoritaria que en el caso de esta cineasta ha seguido en otras películas, como Opus Dei. Una cruzada silenciosa (2006), o recientemente en El Mocito (2011). Sin duda estas obras necesitan ser tratadas en los trabajos sobre la historia reciente. Podríamos agregar que otras películas como el Diario de Agustín(2008) o Héroes Frágiles(2006) realizan el trabajo del historiador desde el presente hacia el pasado para mostrar con la nitidez de la imagen lo que está oculto a la memoria pública: la intervención de la CIA para provocar el Golpe de Estado, la colusión del diario El Mercurio para evitar la investigación sobre las desapariciones forzadas. Estas películas nos llevan a reflexionar sobre el poder, y la siempre presente tentación autoritaria, así podemos recordar la advertencia de Resnais-Cayrol en Noche y Niebla (1955) observando Auchwitz: “¿Quién de nosotros vigila este extraño observatorio para advertirnos de la venida de nuevos torturadores? ¿Verdaderamente tienen otro rostro que el nuestro?”

La memoria sobre el pasado reciente ha sido tratada con perseverancia por varios cineastas, en especial, Patricio Guzmán. La batalla de Chile, la lucha de un pueblo sin armas (1972-1979), solo se ha mostrado de forma parcial en la televisión abierta, aparecen preguntas que no pueden evadirse: ¿A qué se le teme? ¿No debería ser un material obligado en la educación para ver una parte del pasado próximo que solo se visita conceptualmente? Las respuestas son obvias, quedaría explicada en imágenes la contradicción entre la interpretación oficial sobre el Golpe de Estado y los movimientos sociales bregando por una construcción más democrática del país. En este caso no se trata solo de acuerdos sociales explícitos, también puede interpretarse como las limitaciones permisibles para el conocimiento de todos o, en otros términos, de una cierta amnistía, que como lo plantea Ricoeur (2004): "La amnistía solo puede responder a un deseo de terapia social de urgencia, bajo el signo de la utilidad, no de la verdad” (p. 581). Por cierto que Patricio Guzmán no ha cejado y ha dedicado gran parte de su trabajo a revelar lo que queda del pasado al interior de la sociedad, como lo hace en La Memoria Obstinada (1998), para seguir con El Caso Pinochet (2001), o recientemente en La Nostalgia de la Luz (2011), que van armando la historia reciente y las expectativas sociales que permanecen sin resolverse. Por sus repercusiones, en 
este mismo registro, Carmen Luz Parot nos lleva a re-visitar, acompañada por los sobrevivientes, el Estadio Nacional (2001), campo de concentración emblemático, lugar de uso para el deporte nacional, para las elecciones y para eventos musicales, políticos y solidarios.

Poco sabíamos públicamente sobre las autorías de los movimientos sociales en dictadura, había ciertos films, pero sobre todo recuerdos de sobrevivientes, participantes en las protestas, más o menos anónimos, hasta que Sebastián Moreno nos emocionó y nos volvió a esos tiempos, en la Ciudad de los Fotógrafos (2006). Apareció la obra delos fotógrafos de la AFI (Asociación de Fotógrafos Independientes) que solo tratando de proteger manifestantes, guardaron los registros de la época: lugares de entierro de desaparecidos, acciones de la Agrupación de Familiares de detenidos desaparecidos, y tantos y tantas que iban y venían por las calles oponiéndose a la dictadura. No habría muchas palabras para describir esos tiempos que parecen terminados con el Plebiscito y en las formas de la transición a la democracia, sin mirar y pensar ante este documental.

\section{A modo de conclusión}

En el tratamiento de la historia reciente se presentan problemas teóricos y metodológicos a la hora de considerar los archivos provenientes de la subjetividad, representada en las imágenes fílmicas. Entre las dificultades más importantes está la relación del cine con la política, cuando se refiere a las propuestas de distintas memorias en un campo en disputa. En la época de la reproductibilidad técnica, al decir de Benjamin, o de la “civilización de la imagen”, según Rojas Mix, los lenguajes y emblemas permean las prácticas sociales que aparecen reflejadas en las imágenes en movimiento e interceptan el discurso político.

Podría afirmarse que las imágenes en movimiento, así como la oralidad, ya están en la historia y que la historiografía debe interpretar críticamente, utilizando otros archivos, pero no desconociendo las subjetividades, portadoras de representaciones colectivas en periodos de crisis de las confianzas públicas que hemos presentado en algunos autores de la época de las catástrofes. Como bien lo ha expresado Nelly Richard (2010):

"Le corresponde al arte y la literatura, al pensamiento crítico y la crítica cultural, recoger estas marcas de lo incompleto para que lo fisurado y residual del pasado cobre el espesor valorativo que les niegan los saberes totalizadores de la unidad, la síntesis y la recapitulación” (pp. 181-182). 


\section{Referencias bibliográficas}

Arendt, H. (2008). La promesa de la política. España: Paidós.

De Baecque, A. y Delage, C. (1998). De L'Histoire au Cinéma. Paris: Editions Complexe.

Benjamin, W. (2007). La obra de arte en la época de la reproductibilidad técnica. En su Sobre la fotografía (pp. 97-103). Madrid: Edición Pre-textos.

Bloch, M. (2009). Una extraña derrota. Testimonios escritos en 1940. Barcelona: Crítica.

Chartier, R. (1999). Escribir las prácticas: Foucault, De Certeau, Marin. Buenos Aires: Manantial.

Ferro, M. (1974). Le film: une contre-analyse de la societé. En Le Goff, J. y Nora, P. (Eds.), Faire L'histoire. París: Gallimard.

Habermas, J (2000). Sobre el uso público de la Historia. En su La constelación posnacional. Ensayos políticos (pp. 43-55). Barcelona: Paidós.

Kracauer, S. (2009). De Caligari à Hitler. París-Laussane: L’Age d'Homme.

Ricoeur, P. (2004). La memoria, la historia y el olvido. Argentina: Fondo de Cultura Económica.

Richard, N. (2010). Crítica de la memoria (1990-2010). Santiago: Ediciones Universidad Diego Portales.

Rojas, M. (2006). El imaginario. Civilización y cultura en el siglo XXI. Buenos Aires: Prometeo Libros. 